\title{
Coupling Coordinated Development of Space-Industry in Central Plains Urban Agglomeration
}

\author{
Yuhan Yang \\ Jinan University, Guangzhou, China \\ Email:y13539486140@163.com
}

How to cite this paper: Yang, Y. H. (2020). Coupling Coordinated Development of Space-Industry in Central Plains Urban Agglomeration. Modern Economy, 11, 16211640.

https://doi.org/10.4236/me.2020.1110113

Received: September 8, 2020

Accepted: October 26, 2020

Published: October 29, 2020

Copyright $\odot 2020$ by author(s) and Scientific Research Publishing Inc. This work is licensed under the Creative Commons Attribution International License (CC BY 4.0).

http://creativecommons.org/licenses/by/4.0/

(c) (i) Open Access

\begin{abstract}
With the increasing expansion of urban scale and the gradual upgrading of industrial structure, the urbanization level has been continuously promoted. Only by industry and space coordinated development, can the economy be developed rapidly and reasonably, and the quality of urbanization be improved. In recent years, the economic development of central plains urban agglomeration is growing rapidly. However, it is precisely because the central plains urban agglomeration is pursuing the rapid development of the economy, and it has gradually formed a kind of development mode. In this paper, in constructing the index system of urban space and industrial development, using the entropy weight method and the methods of coupling coordination degree model, the measure of central plains urban agglomeration spatial and industrial comprehensive development level and the coupling coordination degree, the results show that most cities are in dissonance. Using vertical analysis, the results show that the spatial pattern centered on Zhengzhou has gradually evolved from the spatial point of view. From the perspective of time series, the urban agglomeration of central plain, the industry is evolving in the fluctuation; the main changes are affected by economic environment and policy. Therefore, several suggestions are proposed for these problems, such as accelerating the industrial upgrading and innovation, scientific distribution and rational use of land, and establishing an innovative mechanism for the coordinated development of industry and space.
\end{abstract}

\section{Keywords}

Central Plains Urban Agglomeration, Industry Development, Coupling Coordinated Development 


\section{Introduction}

At present, the Central Plains city group is one of dozens of city groups in China. It belongs to the relatively active region in China's economy, and is also the hub of China's rapid economic development. From 2017 Henan Province, Anhui Province, Shanxi Province, Shandong Province, Hebei Province statistical yearbook data, it can be obtained that by the beginning of 2017, the GDP of the central Plains city cluster was 6193.353 billion yuan, ranking fourth in China after the Yangtze River Delta, the Pearl River Delta and the Beijing-Tianjin-Hebei region. However, since 2014, the central Plains city group has been blindly pursuing rapid urbanization and economic development, while the traditional urbanization has been blindly pursuing large and comprehensive development, which has resulted in the increasingly unbalanced overall development of the central Plains city group, resulting in the decline of economic efficiency, environmental pollution, waste of resources and other increasingly serious problems. Economist Friedman showed that China is now in a state of excessive urbanization. Urbanization development and urban development capacity should be complementary to each other, and they should develop in a coordinated way. The excessively rapid development of only one side will often cause many problems. The rapid development of urbanization is not a good thing. It is obvious that the central plains city group is in such a state at present. Therefore, for the central Plains city cluster, the first premise to promote economic development and improve the level of urbanization is to clarify the coordination between urban space and industry. Only the coordinated development of space and industry can achieve the goal of solving the problem.

Under the premise that the economic development and urbanization development of the central Plains city cluster are in imbalance, discussing the spatial-industrial coordination degree and development mode of the central Plains city cluster and discussing their rules will play a guiding role in the economic development and urbanization development of the Central Plains city cluster, and provide reference value for the specific implementation of new urbanization strategy.

Since the 1990s, each region has been paying close attention to its own development indicators such as industry, space and population. Many scholars have different researches on this, with different focuses, objects and scopes, which can be summarized as three points: industrial structure theory, urban spatial structure theory, space-industry-population development coordination theory.

Zhang (2015) believes that there are two systems in the process of economic development: industry and urbanization. Song (2014) proposed that in the new period, the Central Plains urban agglomeration should give full play to the radiation driving ability and optimize the industrial structure reasonably. Zhang (2015), it is concluded that industrial structure and economic growth interact, and the development of one side promotes the development of the other. Xia and Yang (2005) believe that the premise of balanced development of regional 
economy should be to solve the problem of spatial coordination. Liu (2015) thinks that although the spatial agglomeration effect of Central Plains urban agglomeration is strong, the diffusion effect is weak. Friedman \& Zhou (2007) analyzed and discussed the importance of establishing inter-city network according to the actual situation, and put forward suggestions and emphases for space development. Xu, He, Chen, \& Zhang (2016) take Fujian Province as an example to explore the coordination degree of spatial -industry - population coupling in 9 cities of Fujian Province. Zhu \& Li (2015) take the Yangtze River Delta urban agglomeration as an example, using the coupling coordination degree model, draw the corresponding conclusions, and put forward reasonable suggestions for the development of urbanization in the Yangtze River Delta region. Zeng and Zhang (2017) take ten urban agglomerations as an example to expand the scope of research, discuss the coordination degree of each urban agglomeration space-industry-population, and compare them, so as to put forward the corresponding conclusions and suggestions.

To sum up, in the space structure theory and the space-industry-population coordinated development theory, foreign researchers rarely mentioned. Taking the central Plains city cluster as the theme to discuss the coordinated development of space-industry, the previous domestic researchers rarely involved. On the basis of previous studies, this paper USES entropy weight method and coupling coordination model to explore the spatial-industrial coupling coordination degree of central Plains city cluster. Through analyzing the coupling coordination degree of the two, problems are found and reasonable Suggestions are put forward.

Although many scholars at home and abroad have done research and analysis on this issue, there are not many researches on the space-industry coupling and coordinated development of central Plains city cluster. The innovation of this paper is that the research object is the central Plains city cluster, not only limited to Henan Province. In the study of the factors affecting the urbanization process, the focus has shifted from resources and environment to the coordinated development of space and industry. By using the coupled coordinated development model, the temporal change of spatial-industrial coupled coordinated development is not only studied, but also studied at the level of spatial pattern. But there are also many shortcomings, such as neglecting the subsystem of the economic system: population. Lack of coordinated analysis of population, space and industry.

\section{The Status Quo and Characteristics}

\subsection{The Status Quo}

1) Status of resources and environment: At present, with the development of urbanization, a variety of problems are coming one after another, the most serious is the problem of resources and environment. Resources and environment can not only support economic and social development, but also restrict it. Starting from 2016, all provinces and cities have issued plans to protect the eco- 
logical environment and continuously increase environmental protection and resource conservation. Under the implementation of this series of measures, the resources and environmental conditions of the central Plains city cluster keep the momentum of improvement on the whole.

However, each city in the central Plains city cluster has different economic development speed, different environmental conditions and different resources. It can be seen from Table 1 that the total amount of waste water discharged from most cities in Shandong Province, Hebei Province and Henan Province has reached more than 40 million tons, and the discharge of exhaust gas and waste has reached more than 4000 tons, so the air quality is not good. The reason is that the cities of Henan Province, Hebei Province and Shandong Province are mainly developed in the secondary industry in recent years, especially the coal mine resources are rich, many of its industrial enterprises are mainly coal mines, so the overall environment is greatly affected. On the contrary, 5 cities in Anhui province and 2 cities in Shanxi Province have made great efforts to develop new industries and upgrade industrial structure in recent years. The tertiary industry is the main industry, and the water resources are relatively rich. Comparatively, the air quality is better and the environment has been improved.

2) Basic situation of space: Central Plains Urban Agglomeration with Zhengzhou City, Kaifeng City, Luoyang City, Pingdingshan City, Xinxiang City, Jiaozuo City, Xuchang City, Luohe City, Jiyuan City, Hebi City, Shangqiu City, Zhoukou City, Shanxi Province Jincheng City, Bozhou City, Anhui Province as the core development areas, linked radiation Anyang City, Puyang City, Sanmenxia City, Nanyang City, Xinyang City, Zhumadian City, Hebei Province

Table 1. Basic information of resources and environment and space in 2016.

\begin{tabular}{ccccccc}
\hline province & $\begin{array}{c}\text { Total water } \\
\text { resources } \\
(100 \text { million } \\
\text { cubic meters })\end{array}$ & $\begin{array}{c}\text { Total effluent } \\
\text { discharge } \\
\text { ten thousand } \\
\text { tons })\end{array}$ & $\begin{array}{c}\text { Total soot } \\
\text { emission } \\
(\mathrm{t})\end{array}$ & $\begin{array}{c}\text { Days with } \\
\text { air quality } \\
\text { standard } \\
(\text { day })\end{array}$ & $\begin{array}{c}\text { Land area } \\
\left(\mathrm{km}^{2}\right)\end{array}$ & $\begin{array}{c}\text { Population } \\
(10,000)\end{array}$ \\
\hline Henan & 337.35 & $402,063.72$ & $428,800.00$ & 196 & 31,679 & $10,788.00$ \\
Changzhi & 9.32 & 4925.02 & $10,211.90$ & 219 & 334 & 343.54 \\
Jincheng & 9.99 & 3112.10 & 6871.70 & 237 & 143 & 232.09 \\
Yuncheng & 11.70 & 2867.90 & 4734.20 & 252 & 1205 & 530.52 \\
Suzhou & 27.85 & 3572.48 & 6913.80 & 228 & 2907 & 654.05 \\
Huaibei & 7.55 & 3661.13 & $12,683.77$ & 241 & 760 & 216.54 \\
Bozhou & 27.00 & 1878.64 & 3412.47 & 258 & 2263 & 646.85 \\
Fuyang & 38.90 & 2500.24 & $10,064.51$ & 242 & 1967 & 1061.55 \\
Bengbu & 21.72 & 1917.02 & 4154.50 & 247 & 611 & 379.52 \\
Xingtai & 10.90 & 6923.00 & $11,283.50$ & 178 & 132 & 731.99 \\
Handan & 11.78 & 5476.00 & $10,896.00$ & 189 & 434 & 949.28 \\
Liaochen & 12.35 & 8264.00 & $13,604.00$ & 180 & 1710 & 603.68 \\
Heze & 21.97 & 8507.00 & $24,063.00$ & 169 & 2261 & 862.60 \\
\hline
\end{tabular}

Note: The data are from the statistical Yearbook of Henan, Anhui, Shanxi, Shandong and Hebei In 2017. 
Handan City, Xingtai City, Shanxi Province, Yuncheng City, Anhui Province, Liaocheng City, Fuyang City, Huaibei City, Bengbu City, Shandong ProvinceHeze City, covering 30 prefecture-level cities in 5 provinces. Involves the city to be broader, the land area is larger, the population total quantity is big. As can be seen from Table 1, by the end of 2016, the total area of the central Plains city cluster is 287,000 square kilometers, with a total population of 175 million people. These cities have compact spatial distribution and high population density.

3) Current Situation of industrial development: By the end of 2016, the GDP of the Central Plains city cluster was 6.193 trillion yuan, making it a region with a high level of economic development. As can be seen from Table 2, the GDP in 2016 was 6193.3253 billion yuan, and the fiscal revenue was 444.649 billion yuan. The gross product of the primary industry was 693.033 billion yuan, accounting for $12 \%$ of the total. The GDP of the secondary industry was 2972.85 billion yuan, accounting for $49 \%$ of the total, and the GDP of the tertiary industry was 2527.37 billion yuan, accounting for $39 \%$ of the total. On the whole, the central Plains city cluster is dominated by the development of the secondary industry.

\subsection{Characteristics}

1) Resource and environment constraints are tightening: For a long time, the central Plains city cluster mainly adopts the extensive economic development model, which is characterized by high investment, high consumption and low income, and is difficult to change in a short time. As can be seen from Table 1 and Table 2, the industrial structure, energy and environmental status of cities in the Central Plains city cluster are very different. Most cities are mainly developed by industrial enterprises with high energy consumption and emission, which leads to resource waste and environmental pollution to a certain extent. Due to the poor endowment and small quantity of environmental resources, coupled with the accelerating process of industrialization and urbanization, the contradiction of resource and environment carrying capacity bottleneck restricting economic development will become more prominent. Therefore, the protection of resources and environment is still the weak link and urgent task in the economic and social development of the central Plains city cluster.

2) Irrational tertiary industrial structure in the Central Plains city cluster: At present, the central Plains city cluster mainly focuses on the development of the secondary industry, supplemented by the coordinated development of the primary and tertiary industries. Therefore, at the present stage, it is necessary to adjust the structure of the tertiary industry, rationally optimize it, and pay attention to the development of the tertiary industry and the new industry, so that the economy can develop reasonably.

3) Uneven development across regions: Among the 30 cities in the central Plains city cluster, there are obvious differences in the development level between the central city Of Zhengzhou and other cities as well as between each 
Table 2. Basic situation of industrial development of central plains city clusters in 2016.

\begin{tabular}{|c|c|c|c|c|c|c|c|c|}
\hline \multirow{2}{*}{$\begin{array}{l}\text { The } \\
\text { city }\end{array}$} & \multirow{2}{*}{$\begin{array}{c}\text { Gross } \\
\text { domestic } \\
\text { product } \\
\text { (one } \\
\text { hundred } \\
\text { million } \\
\text { yuan) } \\
8113.97\end{array}$} & \multirow{2}{*}{$\begin{array}{c}\begin{array}{c}\text { Fiscal } \\
\text { revenue } \\
\text { (one } \\
\text { hundred } \\
\text { million } \\
\text { yuan) }\end{array} \\
1011.18\end{array}$} & \multicolumn{2}{|c|}{$\begin{array}{l}\text { The first } \\
\text { industry } \\
\text { GDP ratio } \\
\text { (100 million } \\
\text { Yuan) (\%) }\end{array}$} & \multicolumn{2}{|c|}{$\begin{array}{l}\text { The second } \\
\text { industry } \\
\text { GDP ratio } \\
\text { (100 million } \\
\text { Yuan) (\%) }\end{array}$} & \multicolumn{2}{|c|}{$\begin{array}{l}\text { The third } \\
\text { industry } \\
\text { GDP ratio } \\
\text { (100 million } \\
\text { Yuan) (\%) }\end{array}$} \\
\hline & & & 156.40 & 1.93 & 3796.90 & 46.79 & 4160.70 & 51.28 \\
\hline Kaifeng & 1755.10 & 113.21 & 287.29 & 16.37 & 703.09 & 40.06 & 757.58 & 43.16 \\
\hline luoyang & 3820.11 & 302.66 & 234.00 & 6.13 & 1805.50 & 47.26 & 1743.40 & 45.64 \\
\hline Nanyang & 3114.97 & 167.07 & 515.5 & 16.55 & 1364.35 & 43.80 & 1235.12 & 39.65 \\
\hline Anyang & 2029.85 & 117.45 & 212.44 & 10.47 & 971.02 & 47.84 & 846.39 & 41.69 \\
\hline Shangqiu & 1989.15 & 117.43 & 386.26 & 19.42 & 823.83 & 41.42 & 779.06 & 39.16 \\
\hline Xinxiang & 2166.97 & 148.06 & 222.89 & 10.40 & 1074.01 & 49.10 & 870.07 & 40.50 \\
\hline Pingdingshan & 1825.14 & 124.46 & 176.75 & 9.68 & 895.05 & 49.04 & 753.34 & 41.28 \\
\hline Xu chang & 2377.71 & 131.89 & 162.48 & 6.83 & 1398.54 & 58.82 & 816.69 & 34.35 \\
\hline Jiaozuo & 2095.08 & 124.18 & 133.95 & 6.50 & 1241.89 & 58.90 & 719.24 & 34.60 \\
\hline Zhoukou & 2260.02 & 103.86 & 457.63 & 20.30 & 1038.00 & 45.90 & 764.4 & 33.80 \\
\hline Xinyang & 2037.80 & 94.65 & 446.05 & 21.90 & 805.87 & 39.60 & 785.87 & 38.50 \\
\hline Zhumadian & 1972.99 & 105.39 & 412.86 & 20.30 & 773.94 & 39.20 & 786.19 & 40.50 \\
\hline Hebi & 771.79 & 55.61 & 61.99 & 8.03 & 503.25 & 65.21 & 206.55 & 26.76 \\
\hline Puyang & 1449.56 & 72.16 & 161.87 & 11.17 & 793.85 & 54.76 & 493.84 & 34.07 \\
\hline Luohe & 1077.90 & 75.99 & 113.75 & 10.57 & 669.00 & 62.07 & 295.00 & 27.36 \\
\hline Sanmenxia & 1325.86 & 100.12 & 123.50 & 9.31 & 748.93 & 56.49 & 453.43 & 34.20 \\
\hline Jiyuan & 538.91 & 36.50 & 23.27 & 4.32 & 350.12 & 64.97 & 165.52 & 30.71 \\
\hline Changzhi & 1269.20 & 98.53 & 60.10 & 4.70 & 646.90 & 51.00 & 562.20 & 44.30 \\
\hline Jincheng & 1151.50 & 89.32 & 50.70 & 4.40 & 618.90 & 53.70 & 481.90 & 41.90 \\
\hline Yuncheng & 1222.30 & 59.11 & 201.60 & 16.50 & 443.80 & 36.30 & 576.90 & 47.20 \\
\hline Suzhou & 1351.82 & 95.62 & 260.18 & 19.20 & 512.83 & 38.00 & 578.80 & 42.80 \\
\hline Huaibei & 799.03 & 59.18 & 61.56 & 7.70 & 450.21 & 56.30 & 282.26 & 36.00 \\
\hline Bozhou & 1046.10 & 87.02 & 206.17 & 19.70 & 404.93 & 38.70 & 435.00 & 41.60 \\
\hline Fuyang & 1401.86 & 133.44 & 302.33 & 21.60 & 557.78 & 39.80 & 541.75 & 38.60 \\
\hline Bengbu & 1385.82 & 133.88 & 200.01 & 14.40 & 609.12 & 44.00 & 576.69 & 41.60 \\
\hline Xingtai & 2236.36 & 111.48 & 273.21 & 12.20 & 1070.14 & 47.90 & 893.01 & 39.90 \\
\hline Handan & 3666.30 & 204.50 & 405.40 & 11.10 & 1783.70 & 48.60 & 1477.20 & 40.30 \\
\hline Liaocheng & 2859.18 & 187.50 & 338.11 & 11.80 & 1414.66 & 49.50 & 106.41 & 38.70 \\
\hline Heze & 2820.18 & 185.04 & 282.08 & 10.00 & 1458.34 & 51.70 & 1079.76 & 38.30 \\
\hline $\begin{array}{l}\text { The central } \\
\text { plains }\end{array}$ & $61,932.53$ & 4446.49 & 6930.33 & 12.00 & $29,728.5$ & 49.00 & $24,224.30$ & 39.00 \\
\hline
\end{tabular}

Note: The data are from the statistical Yearbook of Henan, Anhui, Shanxi, Shandong and Hebei in 2017. 
city. In terms of GDP, the total GDP of the 30 cities in the Central Plains city cluster is 6193.353 billion yuan, among which the GDP of the 18 cities in Henan province is 404.822 billion yuan, accounting for $66.65 \%$ of the total GDP of the central Plains city cluster. Five cities in Anhui province, two cities in Shandong Province, two cities in Hebei Province and three cities in Shanxi Province account for $9.85 \%, 8.92 \%, 8.71 \%$ and $5.87 \%$ of the total GDP of the central Plains city cluster respectively. The per capita GDP of Zhengzhou is the highest $(84,100$ yuan), followed by Jiyuan (73,700 yuan), with a difference of about 10,000 yuan. Among them, the top five cities in per capita GDP are all in Henan province. Fuyang had the lowest per capita GDP at 17,600 yuan, a far cry from Zhengzhou, which had a GDP per capita of about five times that of Fuyang. It can be seen that Zhengzhou and Jiyuan in Henan Province, Handan in Hebei Province, Liaocheng in Shandong Province, Jincheng in Shanxi Province and other cities are developing well, with relatively high per capita GDP, while other cities are relatively low.

4) Different industrial structure distribution among cities: Specifically from the distribution of the three industrial structures, Xinyang city has the highest proportion, accounting for $21.9 \%$ of GDP, while Zhengzhou has the lowest proportion, accounting for $1.93 \%$ of GDP. However, in terms of the development of the secondary industry, hebi city takes the highest proportion, accounting for $65.21 \%$ of GDP, and Jiyuan City takes the second place, accounting for $64.97 \%$ of GDP. The reason for this situation is that Hebi city and Jiyuan City have a small population, rich steel and coal resources, mainly processing and manufacturing industry, and underdeveloped tertiary industry, which leads to a relatively high proportion of secondary industry. Finally from the perspective of the third industry development, accounting for more than the minimum of Hebei city, accounted for $26.76 \%$ of GDP, the highest is in Zhengzhou, accounted for $51.28 \%$ of GDP, as the capital city of Henan province, Zhengzhou city, central city Zhongyuan urban agglomeration industrial structure upgrade faster than peripheral city, new industry and third industry development is rapid, the higher the level of economic development natural. As can be seen from Table 2 and Table 3,

Table 3. Comparison between Zhengzhou and other surrounding central cities in 2016.

\begin{tabular}{ccccccc}
\hline city & $\begin{array}{c}\text { The urban } \\
\text { population } \\
\text { (ten } \\
\text { thousand) }\end{array}$ & $\begin{array}{c}\text { Gross } \\
\text { domestic } \\
\text { product } \\
\text { (one hundred } \\
\text { million yuan) }\end{array}$ & $\begin{array}{c}\text { Total } \\
\text { passenger } \\
\text { traffic by } \\
\text { road } \\
\text { (ten thousand) }\end{array}$ & $\begin{array}{c}\text { Total road } \\
\text { freight } \\
\text { (ten } \\
\text { thousand } \\
\text { tons) }\end{array}$ & $\begin{array}{c}\text { Fiscal } \\
\text { revenue } \\
\text { (one hundred } \\
\text { million yuan) }\end{array}$ & $\begin{array}{c}\text { Number } \\
\text { of employees } \\
\text { on duty } \\
\text { (ten } \\
\text { thousand) }\end{array}$ \\
\hline Zhengzhou & 716.00 & 8113.97 & 11,007 & 19,269 & 1011.18 & 592 \\
Shijiazhuang & 1078.46 & 3214.80 & 11,843 & 19,886 & 314.97 & 570 \\
Jinan & 723.31 & 6536.12 & 5810 & 21,288 & 641.22 & 470 \\
Hefei & 786.90 & 6274.38 & 10,126 & 28,975 & 615.00 & 530 \\
Wuhan & 834.00 & $11,912.61$ & 11,484 & 28,891 & 2423.00 & 550 \\
Xi'an & 883.21 & 7469.85 & 15,733 & 23,011 & 1135.68 & 645 \\
Taiyuan & 364.00 & 2755.00 & 5975 & 25,248 & 283.00 & 239 \\
\hline
\end{tabular}

Note: The data are from the statistical Yearbook of Henan, Anhui, Shanxi, Shandong, Hebei, Shaanxi and Hubei in 2017. 
Zhengzhou has the highest level of economic development in the central Plains city cluster. There are also similarities in the proportion of industrial structure in each city.

5) The radiation driving capacity of the central city is not strong: The central Plains city cluster has a relatively dense urban distribution with a high degree of concentration, mainly expanding outward with Zhengzhou as the core. The superior geographical position causes the central Plains city group to develop quickly on the whole.

However, compared with other urban agglomerations, the gap is larger. The main reason lies in the central city, and the development of the central city determines the development level of urban agglomeration to a large extent. As a central city, only if Zhengzhou has a good development can it drive the development of other cities, so as to promote the overall development of urban agglomeration. However, Zhengzhou lacks the ability to give play to its central city level and fails to drive the development of other cities to a large extent, which directly leads to that the central Plains city group lags behind the Pearl River Delta, Yangtze River Delta, Beijing-Tianjin-Hebei city group and other city groups in economic development.

As can be seen from Table 3, in terms of urban population size, the population of Zhengzhou in 2016 was about 7.16 million, while that of Wuhan, Xi 'an and Shijiazhuang was 8.34 million, 8.831 million and 10.7846 million, respectively. It can be seen that Zhengzhou is far below Shijiazhuang, Wuhan, Xi'an and Hefei, with a large gap. In terms of the number of employees, Zhengzhou is lower than Xi 'an. In terms of transportation, although Zhengzhou has superior traffic conditions, it has some advantages over Jinan and Hefei in terms of the total number of road passenger transport, but it has no advantages compared with other cities. In terms of total freight volume, Zhengzhou is the lowest among several cities, lagging behind other cities, indicating that Zhengzhou has insufficient radiation driving capacity. The overall analysis above shows that Zhengzhou is far behind the surrounding central cities in economic strength.

\section{Horizontal Analysis of the Spatial}

\subsection{Establishment of Indicator System}

In terms of spatial development, previous researchers mainly used indicators such as urban land and green space area to represent the basic situation. Therefore, this paper adopts four indicators: urban land area, urban green space area, per capita road area and urban built-up area. The specific data are shown in Table 4.

In terms of industrial development, previous researchers believed that the level of economic development could be expressed by the proportion of per capita GDP, primary industry, secondary industry and tertiary industry in GDP respectively, and the industrial scale could be expressed by the number of industrial enterprises. Therefore, per capita GDP, the proportion of primary, secondary 
Table 4. Spatial development indicators of central plains city clusters in 2016.

\begin{tabular}{|c|c|c|c|c|}
\hline The city & $\begin{array}{c}\text { Urban land area } \\
\text { (square } \\
\text { kilometers) }\end{array}$ & $\begin{array}{l}\text { Urban green } \\
\text { area (square } \\
\text { kilometers) }\end{array}$ & $\begin{array}{l}\text { Road area per } \\
\text { capita (square } \\
\text { meters) }\end{array}$ & $\begin{array}{l}\text { Built-up area } \\
\quad \text { (square } \\
\text { kilometers) }\end{array}$ \\
\hline Zhengzhou & 1010 & 206.38 & 8 & 457 \\
\hline Kaifeng & 1596 & 51.71 & 16 & 129 \\
\hline luoyang & 879 & 85.98 & 11 & 216 \\
\hline Nanyang & 2135 & 79.37 & 12 & 150 \\
\hline Anyang & 534 & 33.80 & 15 & 82 \\
\hline Shangqiu & 1697 & 26.65 & 10 & 63 \\
\hline Xinxiang & 431 & 47.33 & 15 & 118 \\
\hline Pingdingshan & 443 & 32.26 & 14 & 73 \\
\hline Xu chang & 1099 & 38.05 & 12 & 108 \\
\hline Jiaozuo & 578 & 45.37 & 16 & 113 \\
\hline Zhoukou & 333 & 30.30 & 21 & 70 \\
\hline Xinyang & 3604 & 52.77 & 16 & 94 \\
\hline Zhumadian & 1365 & 32.59 & 25 & 80 \\
\hline Hebi & 679 & 25.42 & 16 & 64 \\
\hline Puyang & 263 & 23.96 & 14 & 59 \\
\hline Luohe & 1020 & 25.50 & 16 & 67 \\
\hline Sanmenxia & 1927 & 22.39 & 11 & 49 \\
\hline Jiyuan & 1894 & 23.06 & 19 & 55 \\
\hline Changzhi & 334 & 31.62 & 10 & 45 \\
\hline Jincheng & 143 & 18.06 & 19 & 31 \\
\hline Yuncheng & 1205 & 21.04 & 29 & 30 \\
\hline Suzhou & 2907 & 41.55 & 28 & 79 \\
\hline Huaibei & 760 & 44.32 & 17 & 85 \\
\hline Bozhou & 2263 & 28.80 & 46 & 62 \\
\hline Fuyang & 1957 & 60.40 & 26 & 124 \\
\hline Bengbu & 611 & 66.53 & 20 & 145 \\
\hline Xingtai & 132 & 29.88 & 12 & 51 \\
\hline Handan & 434 & 99.83 & 12 & 102 \\
\hline Liaocheng & 1710 & 64.99 & 28 & 101 \\
\hline Heze & 2261 & 56.57 & 25 & 125 \\
\hline
\end{tabular}

Note: The data are from the statistical Yearbook of Henan, Anhui, Shanxi, Shandong and Hebei In 2017.

and tertiary industries in GDP and the number of industrial enterprises are adopted in this paper. The specific data are shown in Table 5.

\subsection{Data Standardization and Index Weight Determination}

The data in this paper are obtained from statistical yearbooks of Henan, Anhui, Shanxi, Shandong and Hebei provinces. Some of the data are directly provided 
Table 5. Industrial development indicators of central plains city clusters in 2016.

\begin{tabular}{|c|c|c|c|c|c|}
\hline The city & $\begin{array}{c}\text { Per } \\
\text { capita } \\
\text { GDP (ten } \\
\text { thousand } \\
\text { yuan) }\end{array}$ & $\begin{array}{l}\text { Primary } \\
\text { industries } \\
\text { account for } \\
\text { GDP } \\
\text { Proportion } \\
\quad \%)\end{array}$ & $\begin{array}{l}\text { The secondary } \\
\text { sector accounts } \\
\text { for GDP } \\
\text { Proportion (\%) }\end{array}$ & $\begin{array}{l}\text { The tertiary } \\
\text { industry } \\
\text { accounts } \\
\text { for GDP } \\
\text { Proportion } \\
\quad \%)\end{array}$ & $\begin{array}{l}\text { Number of } \\
\text { industrial } \\
\text { enterprises } \\
\text { (a) }\end{array}$ \\
\hline Zhengzhou & 8.41 & 1.93 & 46.79 & 51.28 & 2897 \\
\hline Kaifeng & 3.85 & 16.37 & 40.06 & 43.16 & 1343 \\
\hline luoyang & 5.64 & 6.13 & 47.26 & 45.64 & 1920 \\
\hline Nanyang & 3.10 & 16.55 & 43.80 & 39.65 & 2470 \\
\hline Anyang & 3.96 & 10.47 & 47.84 & 41.69 & 1120 \\
\hline Shangqiu & 2.73 & 19.42 & 41.42 & 39.16 & 1358 \\
\hline Xinxiang & 3.78 & 10.40 & 49.10 & 40.50 & 1257 \\
\hline Pingdingshan & 3.67 & 9.68 & 49.04 & 41.28 & 899 \\
\hline $\mathrm{Xu}$ chang & 5.45 & 6.83 & 58.82 & 34.35 & 1718 \\
\hline Jiaozuo & 5.92 & 6.50 & 58.90 & 34.60 & 1336 \\
\hline Zhoukou & 2.57 & 20.30 & 45.90 & 33.80 & 1282 \\
\hline Xinyang & 3.17 & 21.90 & 39.60 & 38.50 & 1294 \\
\hline Zhumadian & 2.83 & 20.30 & 39.20 & 40.50 & 1666 \\
\hline Hebi & 4.79 & 8.03 & 65.21 & 26.76 & 562 \\
\hline Puyang & 4.01 & 11.17 & 54.76 & 34.07 & 1010 \\
\hline Luohe & 4.10 & 10.57 & 62.07 & 27.36 & 677 \\
\hline Sanmenxia & 5.89 & 9.31 & 56.49 & 34.20 & 618 \\
\hline Jiyuan & 7.37 & 4.32 & 64.97 & 30.71 & 260 \\
\hline Changzhi & 3.70 & 4.70 & 51.00 & 44.30 & 316 \\
\hline Jincheng & 4.95 & 4.40 & 53.70 & 41.90 & 241 \\
\hline Yuncheng & 2.31 & 16.50 & 36.30 & 47.20 & 454 \\
\hline Suzhou & 2.43 & 19.20 & 38.00 & 42.80 & 1315 \\
\hline Huaibei & 3.64 & 7.70 & 56.30 & 36.00 & 774 \\
\hline Bozhou & 2.06 & 19.70 & 38.70 & 41.60 & 975 \\
\hline Fuyang & 1.76 & 21.60 & 39.80 & 38.60 & 1709 \\
\hline Bengbu & 4.19 & 14.40 & 44.00 & 41.60 & 1160 \\
\hline Xingtai & 3.09 & 12.20 & 47.90 & 39.90 & 1372 \\
\hline Handan & 3.86 & 11.10 & 48.60 & 40.30 & 1376 \\
\hline Liaocheng & 4.79 & 11.80 & 49.50 & 38.70 & 2646 \\
\hline Heze & 3.27 & 10.00 & 51.70 & 38.30 & 3264 \\
\hline
\end{tabular}

Note: The data are from the statistical Yearbook of Henan, Anhui, Shanxi, Shandong and Hebei In 2017.

or calculated from the statistical bulletin of national economic and social development of each city.

First, according to the statistical yearbook of 5 provinces, the data of corresponding indexes of 30 cities should be searched and the initial data matrix 
should be established. Through the observation of the data, it is found that there is a dimensional relationship between the various data. In order to make the data comparable, the range method should be adopted for dimensionless processing of the data, such as Formula (1).

Establish the original matrix, $X=\left(x_{i j}\right)_{m n}, i=1,2, \cdots, n ; j=1,2, \cdots, m$.

Positive indicator:

$$
Y_{i j}=\left(X_{i j}-X_{j \min }\right) /\left(X_{j \max }-X_{j \min }\right)
$$

Inverse index:

$$
Y_{i j}=\left(X_{j \max }-X_{i j}\right) /\left(X_{j \max }-X_{j \min }\right)
$$

where $n$ represents the number of cities, $n$ represents the number of indicators, represents the ith city's JTH indicator, represents the minimum value of the J item index, and represents the maximum value of the J item index. $X_{i j} X_{j \min }$ $X_{j \max }$ Therefore, a new dimensionless matrix is obtained. $Y=\left(Y_{i j}\right)_{m n}$

Determination of index weight, Firstly, the proportion of the JTH index under the i-th city should be calculated, as shown in Formula (3): $P_{i j}$

$$
P_{i j}=x_{i j}^{n} /\left(\sum_{i=1}^{n} x_{i j}^{n}\right)
$$

Then determine the entropy value of the index, as shown in Formula (4): $E_{j}$

$$
E_{j}=-[1 / \ln (m)] \times \sum_{i=1}^{n} p_{i j} \times \ln \left(p_{i j}\right)
$$

Finally, the entropy weight of the index is determined, as shown in Formula (5): $W_{j}$

$$
W_{j}=\left(1-E_{j}\right) /\left(m-\sum_{j=1}^{m} E_{j}\right)
$$

According to the above formula and the data of various indicators, the calculation results are as follows, as shown in Table 6.

Table 6. Space of central plains city cluster in 2016-Industrial development index and weight.

\begin{tabular}{ccc}
\hline system & indicators & The weight \\
\hline \multirow{2}{*}{ industry } & Per capita GDP (ten thousand yuan) & 0.2009 \\
& Proportion of Primary Industry in GDP (\%) & 0.1948 \\
& Proportion of Secondary Industry to GDP (\%) & 0.2069 \\
& Proportion of tertiary industry in GDP (\%) & 0.2073 \\
Number of Industrial Enterprises (Number) & 0.1901 \\
Urban Land area $\left(\mathrm{km}^{2}\right)$ & 0.2405 \\
space & Urban green Area $\left(\mathrm{km}^{2}\right)$ & 0.2482 \\
& Urban Road Area per capita $\left(\mathrm{square}^{2}\right.$ meters) & 0.2637 \\
Urban built-up area $\left(\mathrm{km}^{2}\right)$ & 0.2476 \\
\hline
\end{tabular}

Note: The data are calculated according to relevant formulas and data collation. 


\subsection{Evaluation Method of Coupling Coordination Degree}

By establishing the coupling degree model and finding out the coupling degree, we can know whether the system is coordinated or maladjusted. The coupling degree function formula is (take 2 dimensions as an example):, and is converted to. $C=S /\left[\left(U_{1}+U_{2}\right) / 2\right] \quad C=\left\{\left(U_{1} \times U_{2}\right) /\left[\left(U_{1}+U_{2}\right) / 2\right]^{2}\right\}^{2}$ Where denotes the industrial development evaluation index and denotes the spatial development evaluation index. $U_{1} \quad U_{2}$ The value of coupling degree $C$ is $0-1$. When $C=1$, it indicates that space and industry are completely correlated. When $C=0$, it means that the space is completely independent of the industry. However, there are many shortcomings in using coupling degree alone, so the coupling coordination degree model is further proposed.

In order to better study the space-industry coupling coordination relationship, the coupling coordination degree model (taking 2 dimensions as an example) continues to be introduced here, that is, $D$ represents the coupling coordination degree, $T$ represents the composite index, where. $D=(C \times T)^{1 / 2} \quad T=\alpha U_{1}+\beta U_{2}$ Among them, is the undetermined coefficient, because industry, space are equally important to economic development, so take. $\alpha \quad \beta \quad \alpha=\beta=1 / 2$ The larger $D$ is, the higher the coupling coordination degree is and the higher the correlation degree is.

\subsection{Calculation Results and Main Conclusions}

Through the coupling degree model and the coupling coordination degree model, the spatial-industrial coupling coordination degree of the original urban agglomeration is obtained, and the coupling coordination degree is divided into four levels. At that time, it showed that the central Plains city group and each city were in a highly disordered stage. $R<0.30$ At that time, it indicated that the central Plains city group and each city were in the stage of mild disorder. $0.30 \leq R<0.50$ At that time, it indicated that the central Plains city group and each city were in the stage of mild coordination. $0.50 \leq R<0.70$ At that time, it showed that the central Plains city group and each city were in a highly coordinated stage. $R \geq 0.70$. It can be seen from Table 7 that four cities in Puyang, Changzhi, Jincheng and Xingtai are in the stage of high imbalance. These cities are located on the periphery of the central city, which is less affected by the central city, and the spatial development is extremely slow, and the coupling coordination degree is less than 0.30. Pingdingshan City, Anyang City, Hebi City, Shangqiu City, Xinxiang City, Xuchang City, Jiaozuo City, Luohe City, Zhoukou City, Sanmenxia City, Huaibei City, Handan City 12 cities are in the stage of mild imbalance. They are distributed in the adjacent areas of Zhengzhou City. South Yang City, Xinyang City, Kaifeng City, Luoyang City, Zhumadian City, Jiyuan City, Mozhou City, Fuyang City, Bengbu City, Suzhou City, Liaocheng City, Yuncheng City, Heze City 13 cities are in the mild coordination stage. Zhengzhou is the city in the high coordination stage, which indicates that the urban space and industrial development have reached a higher level, and the 
Table 7. Space-industrial development evaluation index and coupling coordination degree of central plains city cluster in 2016.

\begin{tabular}{|c|c|c|c|c|c|}
\hline The city & $\begin{array}{c}\text { Industrial } \\
\text { development } \\
\text { evaluation } \\
\text { index }\end{array}$ & $\begin{array}{l}\text { Evaluation } \\
\text { of space } \\
\text { development } \\
\text { index }\end{array}$ & $\begin{array}{l}\text { Comprehensive } \\
\text { development } \\
\text { evaluation } \\
\text { index }\end{array}$ & $\begin{array}{c}\text { The } \\
\text { coupling }\end{array}$ & $\begin{array}{c}\text { Degree of } \\
\text { coupling } \\
\text { coordination }\end{array}$ \\
\hline Zhengzhou & 0.65030 & 0.55662 & 0.60346 & 0.98799 & 0.77215 \\
\hline Kaifeng & 0.43870 & 0.25938 & 0.34903 & 0.87238 & 0.55181 \\
\hline luoyang & 0.50178 & 0.27019 & 0.38599 & 0.82811 & 0.56537 \\
\hline Nanyang & 0.48584 & 0.31724 & 0.40154 & 0.91379 & 0.60574 \\
\hline Anyang & 0.41377 & 0.12793 & 0.27085 & 0.52065 & 0.37552 \\
\hline Shangqiu & 0.41161 & 0.15292 & 0.28226 & 0.62410 & 0.41972 \\
\hline Xinxiang & 0.41522 & 0.15950 & 0.28736 & 0.64324 & 0.42993 \\
\hline Pingdingshan & 0.38853 & 0.10735 & 0.24794 & 0.46032 & 0.33784 \\
\hline Xu chang & 0.47748 & 0.16666 & 0.32207 & 0.58855 & 0.43538 \\
\hline Jiaozuo & 0.46701 & 0.17123 & 0.31912 & 0.61658 & 0.44358 \\
\hline Zhoukou & 0.39718 & 0.14459 & 0.27089 & 0.61252 & 0.40734 \\
\hline Xinyang & 0.42648 & 0.37957 & 0.40302 & 0.99324 & 0.63269 \\
\hline Zhumadian & 0.43795 & 0.25300 & 0.34547 & 0.86184 & 0.54566 \\
\hline Hebi & 0.37816 & 0.12352 & 0.25084 & 0.55109 & 0.37180 \\
\hline Puyang & 0.40016 & 0.07582 & 0.23799 & 0.28697 & 0.26134 \\
\hline Luohe & 0.37175 & 0.14898 & 0.26037 & 0.66747 & 0.41688 \\
\hline Sanmenxia & 0.42777 & 0.16214 & 0.29495 & 0.63560 & 0.43298 \\
\hline Jiyuan & 0.43258 & 0.22043 & 0.32650 & 0.80004 & 0.51109 \\
\hline Changzhi & 0.34382 & 0.05757 & 0.20069 & 0.24147 & 0.22014 \\
\hline Jincheng & 0.37287 & 0.07547 & 0.22417 & 0.31359 & 0.26514 \\
\hline Yuncheng & 0.34484 & 0.22602 & 0.28543 & 0.91523 & 0.51111 \\
\hline Suzhou & 0.40381 & 0.39142 & 0.39761 & 0.99952 & 0.63041 \\
\hline Huaibei & 0.36783 & 0.17261 & 0.27022 & 0.75606 & 0.45200 \\
\hline Bozhou & 0.37111 & 0.44402 & 0.40757 & 0.98406 & 0.63330 \\
\hline Fuyang & 0.40934 & 0.36475 & 0.38704 & 0.99337 & 0.62006 \\
\hline Bengbu & 0.43318 & 0.24891 & 0.34104 & 0.85935 & 0.54136 \\
\hline Xingtai & 0.40423 & 0.05481 & 0.22952 & 0.17687 & 0.20148 \\
\hline Handan & 0.42662 & 0.19946 & 0.31304 & 0.75404 & 0.48584 \\
\hline Liaocheng & 0.53434 & 0.35092 & 0.44263 & 0.91599 & 0.63675 \\
\hline Heze & 0.52212 & 0.37540 & 0.44876 & 0.94726 & 0.65199 \\
\hline $\begin{array}{c}\text { Central Plains } \\
\text { City Cluster }\end{array}$ & 0.42854 & 0.22528 & 0.32691 & 0.81604 & 0.51650 \\
\hline
\end{tabular}

Note: The data are calculated according to relevant formulas and data collation.

coordination degree of the two is higher, and the coupling degree has reached more than $90 \%$. there are great differences in the coupling coordination degree of the central Plains city group and various cities. As a whole, the coupling de- 
gree of Central Plains urban group is 0.42854 , which is in the stage of mild imbalance.

According to the above data and the hierarchical division of coupling coordination degree, the 30 cities in the Central Plains city cluster can be divided into the following four types:

1) Highly maladjusted class

There are puyang city, Changzhi City, Jincheng city and Xingtai City in the stage of high disorder. This shows that the space and industrial development of these four cities have serious dissonance. The main reason for this phenomenon is that the economic development of these cities is slow. At the same time, under the constraints of resources and environment, they pay attention to environmental protection and resource conservation, which inevitably leads to the loss of one city and the loss of the other.

2) Mild disorder

In the stage of mild disorder of city of pingdingshan, anyang, hebi city, shangqiu, xinxiang, the authors, jiaozuo, luohe city, zhoukou city, sanmenxia city, huaibei city, handan city, 12 cities, they are distributed in the adjacent area of zhengzhou city, the central city of radiation effect is good, good industrial development foundation, but spatial development relative lag, the coupling coordination degree is low.

3) Mild coordination

Cities in the mild coordination stage include Nanyang City, Xinyang City, Kaifeng City, Luoyang City, Zhumadian City, Jiyuan City, Haizhou City, Fuyang City, Bengbu City, Suzhou city, Liaocheng City, Yuncheng City and Heze City. These cities are constantly optimizing in all aspects, showing a reasonable structure initially, but also laid a foundation for the coordinated development of the economy.

4) Highly coordinated classes

The city in the highly coordinated stage is Zhengzhou, which indicates that both urban space and industrial development have reached a high level, and their coordination degree is high, with the coupling degree reaching more than $90 \%$. It can be seen that Zhengzhou has a great advantage in spatial-industrial coordinated development. As a central city, Zhengzhou has a solid foundation of space and industrial development, and its degree of coupling coordination is higher than other cities.

\section{Longitudinal Analysis}

\subsection{Changes in the Pattern of Development}

Firstly, the data of each index of each city in 2008 was searched, and the weight of each index was calculated according to the formula in Chapter THREE. Then, a model was established to figure out the space-industry coupling coordination degree of the central Plains city cluster in 2008. The specific data are shown in Table 8. 
Table 8. Spatial-industrial development evaluation index and coupling coordination degree of central plains city cluster in 2008 .

\begin{tabular}{|c|c|c|c|c|c|}
\hline The city & $\begin{array}{c}\text { Industrial } \\
\text { development } \\
\text { evaluation } \\
\text { index }\end{array}$ & $\begin{array}{c}\text { Evaluation of } \\
\text { space } \\
\text { development } \\
\text { index }\end{array}$ & $\begin{array}{c}\text { Comprehensive } \\
\text { development } \\
\text { evaluation } \\
\text { index }\end{array}$ & $\begin{array}{l}\text { The } \\
\text { coupling }\end{array}$ & $\begin{array}{c}\text { Degree of } \\
\text { coupling } \\
\text { coordination }\end{array}$ \\
\hline Zhengzhou & 0.72411 & 0.46690 & 0.59550 & 0.90890 & 0.73570 \\
\hline Kaifeng & 0.46614 & 0.15169 & 0.30891 & 0.54901 & 0.41182 \\
\hline luoyang & 0.56155 & 0.25898 & 0.41027 & 0.74654 & 0.55342 \\
\hline Nanyang & 0.47574 & 0.29330 & 0.38452 & 0.89061 & 0.58520 \\
\hline Anyang & 0.42965 & 0.18676 & 0.30821 & 0.71357 & 0.46896 \\
\hline Shangqiu & 0.40595 & 0.19858 & 0.30227 & 0.77851 & 0.48510 \\
\hline Xinxiang & 0.45818 & 0.20158 & 0.32988 & 0.72036 & 0.48748 \\
\hline Pingdingshan & 0.44189 & 0.15190 & 0.29690 & 0.57989 & 0.41493 \\
\hline $\mathrm{Xu}$ chang & 0.47738 & 0.14011 & 0.30875 & 0.49236 & 0.38989 \\
\hline Jiaozuo & 0.50585 & 0.21133 & 0.35859 & 0.69115 & 0.49783 \\
\hline Zhoukou & 0.41236 & 0.21052 & 0.31144 & 0.80102 & 0.49947 \\
\hline Xinyang & 0.45042 & 0.41030 & 0.43036 & 0.99566 & 0.65459 \\
\hline Zhumadian & 0.44542 & 0.23219 & 0.33881 & 0.81175 & 0.52443 \\
\hline Hebi & 0.41718 & 0.17138 & 0.29428 & 0.68161 & 0.44787 \\
\hline Puyang & 0.39576 & 0.10654 & 0.25115 & 0.44685 & 0.33500 \\
\hline Luohe & 0.40716 & 0.23345 & 0.32030 & 0.85836 & 0.52434 \\
\hline Sanmenxia & 0.46596 & 0.06917 & 0.26757 & 0.20270 & 0.23289 \\
\hline Jiyuan & 0.49147 & 0.28536 & 0.38842 & 0.86417 & 0.57936 \\
\hline Changzhi & 0.39912 & 0.16628 & 0.28270 & 0.68959 & 0.44153 \\
\hline Jincheng & 0.41257 & 0.13971 & 0.27614 & 0.57141 & 0.39723 \\
\hline Yuncheng & 0.37888 & 0.19770 & 0.28829 & 0.81225 & 0.48390 \\
\hline Suzhou & 0.43049 & 0.35053 & 0.39051 & 0.97915 & 0.61836 \\
\hline Huaibei & 0.41179 & 0.18348 & 0.29764 & 0.72744 & 0.46531 \\
\hline Bozhou & 0.41307 & 0.42074 & 0.41691 & 0.99983 & 0.64563 \\
\hline Fuyang & 0.40749 & 0.26804 & 0.33776 & 0.91660 & 0.55641 \\
\hline Bengbu & 0.44235 & 0.22281 & 0.33258 & 0.79400 & 0.51388 \\
\hline Xingtai & 0.47110 & 0.18240 & 0.32675 & 0.64775 & 0.46006 \\
\hline Handan & 0.50040 & 0.32433 & 0.41237 & 0.91092 & 0.61289 \\
\hline Liaocheng & 0.57000 & 0.49191 & 0.53096 & 0.98921 & 0.72473 \\
\hline Heze & 0.49015 & 0.35227 & 0.42121 & 0.94714 & 0.63162 \\
\hline $\begin{array}{l}\text { Central Plains } \\
\text { City Cluster }\end{array}$ & 0.45865 & 0.24268 & 0.35066 & 0.81932 & 0.53601 \\
\hline
\end{tabular}

Note: The data are calculated according to relevant formulas and data collation.

First of all, from the overall situation of urban space-industrial system development in the Central Plains city cluster from 2008 to 2016, it can be seen that Zhengzhou is still the dominant city. The central Plains city cluster is mainly 
developed with Zhengzhou as the center, and there is still a large gap between other cities and Zhengzhou. In 2008, The comprehensive development level of Zhengzhou ranked first, at 0.5955 , while Liaocheng and Xinyang were lower than Zhengzhou.

Secondly, from the perspective of the development of urban space and industrial system in the central Plains city cluster from 2008 to 2016, the development speed of urban space and industry is not consistent.

By comparing the coupling and coordination degrees of cities in the Central Plains city cluster in 2008 and 2016. On the whole, the spatial-industrial coupling coordinated development of the central Plains city cluster is not obvious, but the coupling development level of each city has been improved to some extent. At the same time, the central Plains city group has formed a coordinated development zone with Zhengzhou as the main city and Nanyang City, Luoyang City, Liaocheng City, Heze City and Xinyang City as the auxiliary cities.

\subsection{Time Series Changes}

First of all, from the perspective of the comprehensive development level of the central Plains city group, the comprehensive development level of the Central Plains city group fluctuates continuously from 2008 to 2016. By Table 9, you can see that the comprehensive development level according to the development trend, can be roughly divided into four stages, 2008-2010, the central plains urban agglomeration comprehensive development level has a certain decline, but in 2010-2012, the central plains urban agglomeration comprehensive development level has increased, in 2012-2015, the central plains urban agglomeration comprehensive development level oscillation declines, the lowest level in 2015, 2015-2016 for the sharp rise in zhongyuan urban agglomeration comprehensive development level. Obviously, the comprehensive development level of The

Table 9. Spatial-industrial development evaluation index and coupling coordination degree of central plains city cluster from 2008 to 2016.

\begin{tabular}{cccccc}
\hline year & $\begin{array}{c}\text { Evaluation } \\
\text { of space } \\
\text { development } \\
\text { index }\end{array}$ & $\begin{array}{c}\text { Industrial } \\
\text { development } \\
\text { evaluation } \\
\text { index }\end{array}$ & $\begin{array}{c}\text { Comprehensive } \\
\text { development } \\
\text { evaluation } \\
\text { index }\end{array}$ & $\begin{array}{c}\text { The } \\
\text { coupling }\end{array}$ & $\begin{array}{c}\text { Degree of } \\
\text { coupling } \\
\text { coordination }\end{array}$ \\
\hline 2008 & 0.24268 & 0.45865 & 0.35066 & 0.81932 & 0.53601 \\
2009 & 0.25587 & 0.42310 & 0.33948 & 0.88235 & 0.54731 \\
2010 & 0.22126 & 0.44454 & 0.33290 & 0.78773 & 0.51209 \\
2011 & 0.24387 & 0.43231 & 0.33809 & 0.85070 & 0.53629 \\
2012 & 0.24463 & 0.44731 & 0.34597 & 0.83577 & 0.53773 \\
2013 & 0.25728 & 0.42647 & 0.34188 & 0.88129 & 0.54890 \\
2014 & 0.23216 & 0.41298 & 0.32257 & 0.84906 & 0.52334 \\
2015 & 0.21590 & 0.40089 & 0.30840 & 0.82819 & 0.50538 \\
2016 & 0.22528 & 0.42854 & 0.32691 & 0.81604 & 0.51650 \\
\hline
\end{tabular}

Note: The data are calculated according to relevant formulas and data collation. 
Central Plains city cluster was the highest in 2008, which was 0.35066 . Thanks to the central China Rising Plan released in 2006, the central Plains city cluster was given unprecedented opportunities and challenges. At the same time, the central Plains city group fell from 2008 to 2010, which was just the result of the financial crisis. On the contrary, it rose twice from 2010 to 2012 and from 2015 to 2016, benefiting from the development plan of Central Plains city cluster proposed in 2010 and 2016. From this point of view, stable economic environment and policy support will have a certain role in promoting the comprehensive development level of the city. Therefore, the economic environment and relevant policies are the important reasons for the continuous fluctuation of the comprehensive development level of the central Plains city cluster.

Secondly, the analysis of the space and industrial development level of the central Plains city cluster can reveal the main factors affecting the development of the central Plains city cluster and the main contradiction of the coordinated development of space and industry. It can be seen that in recent years, the central Plains city clusters are dominated by industrial development, and there is a big gap between space and industrial development level, which reveals the main contradiction between space and industrial development imbalance.

Finally, by analyzing the coupling coordination degree of the central Plains city agglomeration, it can be concluded that the spatial-industrial coupling coordination degree of the central Plains city agglomeration evolves in the fluctuation. The first phase is from 2008 to 2010, during which the level of coupling coordination is in the range of 0.51 to 0.55 , although there has been a sharp decline in 2010. In the second stage, from 2010 to 2012, the coupling coordination level rose steadily, reaching about 0.53. In the third stage, from 2012 to 2015, the level of coupling coordination first rose and then continued to decline, but reached the highest level in 2013. The fourth stage is from 2015 to 2016, and the coupling coordination level has a certain rising trend, rising to 0.5165 . On the whole, in recent years, the coordination degree of space-industry coupling in central Plains city cluster has been in the stage of mild coordination.

\subsection{Main Conclusions}

From the perspective of pattern change, the spatial-industrial coupling coordination degree of central Plains city cluster presents obvious spatial differentiation. From 2008 to 2016, the overall level of urban space-industrial coupling coordination development of central Plains city cluster has been improved to a certain extent. Zhengzhou, as the central city of Central Plains city cluster, has a higher coordination degree than other cities. Moreover, the overall pattern of the central Plains city cluster is also gradually changing, gradually becoming a coordinated regional development pattern with Zhengzhou as the center and $\mathrm{Na}$ nyang City, Luoyang city, Liaocheng City, Heze City and Xinyang City as the auxiliary.

From the perspective of time series changes, the spatial and industrial development of central Plains city cluster generally evolves in fluctuation, and the 
evolution process can be roughly divided into four stages: the first stage is from 2008 to 2010, which is dominated by industrial development. However, due to the impact of the financial crisis, the coordinated development level declines to a certain extent. The second stage is from 2010 to 2012. Due to policy support, the level of industrial, spatial and comprehensive development has rebounded, and the development model is still industry-led. The third stage is the period from 2012 to 2015. Due to the economic recession, the level of all aspects continues to decline. The fourth stage is from 2015 to 2016. After experiencing the recession, the central Plains city cluster recovered rapidly and the degree of system coordination increased. However, the degree of coupling and coordination between space and industry is still relatively low, which also becomes the main contradiction restricting the spatial-industrial coordinated development of central Plains city cluster.

It can be seen from the above conclusions that the central Plains city cluster is in a state of mild coordination. The sound development of urbanization cannot be separated from the coordinated development of space-industry. Each city in the central Plains city cluster should pay attention to the coordinated development of space-industry, accelerate industrial upgrading and innovation, scientifically distribute and rationally utilize land, so that the space-industry can develop in a balanced way, so as to promote the further development of urbanization and economy.

\section{Conclusions and Suggestions}

Although the Central Plains urban agglomeration in recent years is dominated by industrial development, it also promotes economic development. However, according to the calculation, with the acceleration of urbanization, the coupling coordination degree between space and industry in Central Plains urban agglomeration is at the level of barely coordination, and more problems and contradictions appear. Therefore, in order to further improve the quality of economic development and the level of urbanization, governments at all levels should actively formulate plans and take reasonable policy measures.

\subsection{Accelerate Industrial Upgrading and Innovation}

On the whole, it is pointed out in the 2016 Central Plains city cluster development plan that the central Plains city cluster should be upgraded into a national advanced manufacturing and service industry base as well as a demonstration area for green ecological development. The proportion of the tertiary industry and emerging industries should be increased and the tertiary industry should be developed intensively. Therefore, the central Plains city cluster should actively carry out industrial upgrading and innovation. As for the past structural model, we should continue to retain and adhere to the good things, and should transform and upgrade those that deviate from the current economic development model.

In the process of industrial upgrading and innovation, the market plays an 
important role. However, in terms of the market mechanism, the central Plains city cluster is in the primary stage, and the market mechanism is not perfect. Therefore, the central Plains city group should perfect the market mechanism, improve the competitiveness, so as to promote the development of the market economy. In the process of improving the market mechanism, it is necessary to summarize the experience of developed countries, combine with the market situation of China, and use certain technologies to improve the market mechanism and realize the industrial upgrading and innovation of the central Plains city cluster. In the aspect of enterprise, innovation and upgrading of enterprise difficulty is bigger, and the emphasis and difficulty in urban industrial structure optimization innovation, governments at all levels to enterprises in the industrial upgrading, technological innovation and market expansion to give greater support, so as to promote enterprise innovation and industry upgrading, stable economic development. At the same time, in addition to government support, enterprises' own innovation and upgrading are also the top priorities. Therefore, enterprises should cultivate their own innovation ability, independent research and development, improve their comprehensive strength, and realize industrial upgrading and innovation in the central Plains city cluster. In the process of industrial upgrading and innovation, we should combine the market with the government, make full use of industrial policies as guidance, strengthen the capacity of independent innovation, and change the previous extensive development mode into intensive development mode.

\subsection{Scientific Layout and Rational Use of Land}

At present, with the increasing contradiction between supply and demand of land in China, strengthening land management and scientific use of land have become the fundamental approach and inevitable choice to solve this problem. To a certain extent, the government should enhance the consciousness of innovation, change the space design, scientifically arrange the urban space, rationally use the land, and make the urban land more sustainable development. In terms of land use, the government should clarify the total amount of land, appropriately control the scale of land use and formulate reasonable land use policies. At the same time, the government should strengthen legislation to make land use policy more authoritative. In the scientific and rational use of urban space, the role of land administration departments should be brought into play. Administrative departments should fully investigate all aspects of land, understand the problems and deficiencies of land use, understand the functions of land in different areas, and tap the potential, so as to make a scientific layout, formulate the best development and utilization plan, and give full play to the maximum benefits of land.

\subsection{Establish an Innovation Mechanism for the Coordinated Development of Space and Industry}

The government should take space and industry into consideration when for- 
mulating the urban development plan. The result of the adjustment of industrial structure will finally be presented in the form of space, which will also affect the result of spatial optimization. Therefore, the relevant policies should be considered and implemented at the same time in order to solve these two problems comprehensively. The improvement of industrial level will promote economic growth and urban development. Once the city develops too fast and has a certain competitiveness, the labor force and capital will increase, leading to further development of space, and thus providing more space for industrial development. If the spatial development stagnates, it will also have a certain influence on the industrial development, which will inevitably affect the comprehensive development level of the city. Therefore, the government should give more rights of urban development to the market, supervise the service market, make industrial development and spatial development complement and influence each other, make industrial development drive spatial development, spatial development promote industrial development, and establish an innovative mechanism for coordinated development of space and industry.

\section{Conflicts of Interest}

The author declares no conflicts of interest regarding the publication of this paper.

\section{References}

Friedman, J., \& Zhou, K. (2007). New Urban Regions in China: Intercity Networks. Journal of Urban Planning, No. 1, 1-4.

Liu, Z. B. (2015). A Study on Spatial Structure Effect of Central Plains Urban Agglomeration. Kaifeng: Henan University.

Song, Q. (2014). A Study on the Optimization of Industrial Structure of Central Plains Urban Agglomerations. Tianjin: Tianjin University of Technology.

Xia, B. L., \& Yang, D. M. (2005). Analysis of Space Development Strategy of Central Plains Urban Agglomeration. China Urban Planning Annual Conference, No. 9, 219-224.

Xu, X. X., He, Y. D., Chen, L. X., \& Zhang, Y. (2016). Analysis of Spatial-Temporal Coupling Characteristics of Population-Space-Industry Urbanization in Fujian Province. Development Research, No. 1, 60-64.

Zeng, P., \& Zhang, F. (2017). Comparison of the Coupling Coordination Degree of "Industry-Population-Space” in Ten City Clusters. Statistics and Decision-Making, No. 10, 94-98.

Zhang, B. (2015). The Impact of Industrial Structure Adjustment on Economic Growth in Japan. International Business and Management, No. 2, 57-63.

Zhang, L. P. (2015). Research on the Coupling Effect of Industrial Agglomeration and Urbanization in Central Plains City Clusters. Modern City Research, No. 7, 52-57.

Zhu, J. L., \& Li, Z. L. (2015). Research on the Coordinated Development of Industry, Population and Space Coupling in Urban Agglomeration of Yangtze River Delta. China Population Resources and Environment, No. 2, 75-82. 